\title{
Acute and subacute toxicity study of the methanolic extract of olea europea. $L$ leaves in Wistar rat
}

\author{
Ibrahim Hinad, Youssef S'hih, Radia El Gui, Aboubaker Elhessni, Abdelhalim Mesfioui, and Moulay laarbi \\ Ouahidi
}

Laboratory of Biology and Health, Faculty of Sciences, Ibn Tofail University in Kenitra, Morocco.

\begin{abstract}
Olea europea.L (olive tree) is a plant widely used in the world. Its leaves have an extensive use in traditional herbal medicine to prevent and/or treat several diseases especially in Mediterranean regions. Despite this, research into the study of its toxicity is very limited in the literature. For this, this study aims to study the acute and subacute toxicity of methanolic extract olive leaves in Wistar rats. To study acute toxicity, four dose levels $(50,300,2000$ and $5000 \mathrm{mg} / \mathrm{kg}$ body weight) were tested by single oral administration to Wistar rats. The subacute toxicity for 28 days was conducted by daily oral administration of methanolic extract of olive leaves at doses 1000,2000 and $3000 \mathrm{mg} / \mathrm{kg}$ in rats Wistar. After fourteen days of the administration of escalating doses, no deaths were recorded in the animals and no clinically detectable signs were observed. The results of subacute toxicity showed that the body weight of rats was not significantly changed by administration of methanolic extract of olive leaves. Monitoring of the behavior of the rats during the study showed the appearance of some manifestations of tremor, agitation and diarrhea in rats treated with the dose of $3000 \mathrm{mg} / \mathrm{kg}$. Grosse examination of the kidneys and liver revealed no changes in those organs and histopathological examination showed congestion and inflammation of the fat in rats treated with the dose of $3000 \mathrm{mg} / \mathrm{kg}$. the hematological profile showed no significant changes of the measured hematological parameters. Olive leaves should be used with care and caution since its methanolic extract caused some signs of toxicity and may affect the liver at repeated dose. however, more studies are needed to verify and clarify the toxic aspect of olea europea. $L$ leaves.
\end{abstract}

Key words: Olea europea. L, acute toxicity, subchronic toxicity, Wistar rat.

\section{Introduction}

Natural herbs have a long history of use in the counteractive action against a various human aliment. The herbs global presence in modern medical and healthcare systems has developed as a result of their continued use[1]. A lot of research has been done to find the biologically active compounds in medicinal plants and many successful medicines have been developed from herbal plants as a result of researcher's efforts[2]. Plants produce a wide range of metabolites, some of which can be beneficial to human healthcare and others that may be harmful[3]. The toxicity of pharmaceutical drugs depends on the dose of the administration; they can be beneficial for some doses and toxic for others[4]. Only a few conventional herbal medicines have been tested for efficacy and safety despite their widespread use[5]. Olea europea.L, also known as the olive tree, has been grown for centuries for its fruits and oil. Olea europea.L crops are now grown in several parts of the word and come in a variety of cultivars, some of which are specific to certain areas[6]. Several studies have shown that olea europea. L has many activities in vivo and in vitro; management of hypercholesterolemia and reducing the risk of atherosclerosis[7]. Olive leaves has an important influence on diabetes mellitus and attenuate inflammatory markers[8], Antimicrobial activity[9], Antiproliferative against breast cancer cells[10] and Anti-inflammatory effects[11]. Olea europaea.L leaves are widely used in the traditional treatment of diabetes in Morocco[12], [13]. However, studies regarding its toxicity are limited in the literature. Therefore, the aim of this study is to investigate acute and subacute oral toxicity of methanolic extract of olive leaves (MEOL) in Wistar rats.

\section{Materials and methods \\ Preparation of the extract}

Olive leaves were collected from Ksar elkebir region (North-western Morocco). The leaves were dried then ground into powder.40g of powder was subjected to extraction with $250 \mathrm{ml}$ of methanol by a soxhlet for $6 \mathrm{~h}$. The extract obtained was then concentrated by evaporation using a rotary 
evaporator until a pasty extract was obtained which was then dried to obtain a dry extract.

\section{Study animals}

Rats Wistar were obtained from animal facility of the science faculty- Ibn Tofail University, kenitra, Morocco. The rats were weighed and divided into groups and acclimatized to laboratory conditions with free access to food and water for 7 days before the commencement of experiment.

\section{Acute toxicity}

The study was conducted according to the OCDE protocol [14]. It's failed to find out the dose which could cause $100 \%$ death of rats. The animals were fasted during the night preceding the experiment (the were deprived of food and not water). Rats were given, by gastroesophageal gavage, four dose levels;50, 300, 2000 and $5000 \mathrm{mg} / \mathrm{kg}$ (limit test) of MEOL. Treated rats were observed for 14 days to follow the probable appearance of signs of acute poising including mortality and behavioral modifications, respiratory and digestive system changes, morphological changes (eyes color, skin changes...). It's also necessary to observe the appearance of signs such as diarrhea, lethargy, coma and sleep, tremors and convulsion.

\section{Subacute toxicity}

Rats were divided into 4 groups each composed of 6 rats. Groupe 1 served as controls receiving distilled water and fed regular diet. Groupe 2: rats of this group received a daily dose of $1000 \mathrm{mg} / \mathrm{mg} / \mathrm{kg}$. Group3: the rats receive a dose of $2000 \mathrm{mg} / \mathrm{kg}$ and rats of group 4 received a dose of $3000 \mathrm{mg} / \mathrm{kg}$ of MEOL throughout the duration of the study (28 days).

The rats are deprived of food 2 hours before administration of the plant and then observed 4 hours after taking the dose. body weight was measured after each week.

\section{Hematological analyses and histopathological examination}

After 28 days of treatment, the rats were anesthetized, and blood was collected for use in hematological analyzes. then, the animals were sacrificed to recover the liver and kidneys which were stored in $10 \%$ formalin until the performance of histological examinations according to the standard protocol using hematoxylin-eosin staining.

\section{Statistical analyses}

The statistical significance was compared between the control and experimental groups using $t$-student and by one-way analysis of variance (ANOVA) using Sigmaplot version 11.0 and Graphpad Prism version 5.0 software. The values are expressed as the mean \pm the standard deviation (Mean \pm SD). P values less than $0.05(p<0.05)$ are considered statistically significant.

\section{Results}

\section{Acute toxicity}

Oral administration of a single dose $(50,300,2000$ and $5000 \mathrm{mg} / \mathrm{kg}$ ) of MEOL to Wistar rat did not cause any death. Animals did not show any signs of sickness and continued to lead a normal life within the fourteen day of the study.

\section{Subacute toxicity}

\section{Evolution of the weight of the rats}

All groups of animals showed a positive weight change (Table 1). However, there is no significant difference between the groups of treated rats (group 1, group 2 and group3) and the group control (Student Test less than 5\%).

\section{Clinical signs of intoxication}

The animals of the group control, group 1 and group 2 did not show any signs of intoxication, while the animals of group 3 showed some signs such as diarrhea, manifestations of tremor and agitation as shown in (Table 2).

\section{Hematological parameters}

The results of hematological parameters measured indicate that there were no significant differences between the experimental groups $(2,3,4)$ and the control group (Table 3).

\section{Grosse and histopathological examination of organ rats}

Macroscopic examination of kidney and liver of rats showed no changes in the exterior appearance of these organs for all groups treat by the extract as well as group control.

Histopathological examination showed that the liver and kidney of rats of group control, group1 and group 2 were normal without any changes. However, those of rats of group 4 (treated with $3000 \mathrm{mg} / \mathrm{kg}$ ) showed some changes as well as steatosis in liver (figure 2) and congestion and inflammation of the fat in the kidney (figure 4). 
Table 1: weekly evolution of the average weight of animals

\begin{tabular}{lllllll}
\hline Group & Initial weight & Week 1 & Week 2 & Week 3 & Week 4 & Variation \\
\hline Control & $110,20 \pm 20$ & $116,45 \pm 15$ & $122,43 \pm 16$ & $124,40 \pm 16$ & $127,30 \pm 16$ & $+17,10$ \\
\hline $1000 \mathrm{mg} / \mathrm{kg}$ & $122,40 \pm 30$ & $126,10 \pm 20$ & $130,17 \pm 13$ & $136,30 \pm 18$ & $140,05 \pm 23$ & $+17,67$ \\
\hline $2000 \mathrm{mg} / \mathrm{kg}$ & $141,20 \pm 12$ & $143,09 \pm 19$ & $147,40 \pm 20$ & $154,19 \pm 18$ & $157,30 \pm 24$ & $+16,1$ \\
\hline $3000 \mathrm{mg} / \mathrm{kg}$ & $135,10 \pm 23$ & $137,90 \pm 19$ & $143,50 \pm 18$ & $148,09 \pm 09$ & $153,12 \pm 18$ & $+18,03$ \\
\hline
\end{tabular}

Table 2: monitoring of clinical signs and animal behavior

\begin{tabular}{|c|c|c|c|c|}
\hline Day & Group Control & Group 1 & Group 2 & Group 3 \\
\hline 1 & - & - & - & - \\
\hline 2 & - & - & - & - \\
\hline 3 & - & - & - & - \\
\hline 4 & - & - & - & - \\
\hline 5 & - & - & - & - \\
\hline 6 & - & - & - & - \\
\hline 7 & - & - & - & - \\
\hline 8 & - & - & - & - \\
\hline 9 & - & - & - & - \\
\hline 10 & - & - & - & - \\
\hline 11 & - & - & - & - \\
\hline 12 & - & - & - & - \\
\hline 13 & - & - & - & Diarrhea \\
\hline 14 & - & - & - & Agitation \\
\hline 15 & - & - & - & Diarrhea \\
\hline 16 & - & - & - & $\begin{array}{c}\text { Agitation } \\
\text { Manifestations of } \\
\text { tremor } \\
\text { Diarrhea } \\
\end{array}$ \\
\hline 17 & - & - & - & $\begin{array}{c}\text { Agitation } \\
\text { Manifestations of } \\
\text { tremor } \\
\text { Diarrhea }\end{array}$ \\
\hline 18 & - & - & - & $\begin{array}{l}\text { Agitation } \\
\text { Diarrhea }\end{array}$ \\
\hline 19 & - & - & - & $\begin{array}{l}\text { Agitation } \\
\text { Diarrhea }\end{array}$ \\
\hline 20 & - & - & - & $\begin{array}{l}\text { Agitation } \\
\text { Diarrhea }\end{array}$ \\
\hline 21 & - & - & - & Diarrhea \\
\hline 22 & - & - & - & Diarrhea \\
\hline 23 & - & - & - & Diarrhea \\
\hline 24 & - & - & - & Diarrhea \\
\hline 25 & - & - & - & Diarrhea \\
\hline 26 & - & - & - & Diarrhea \\
\hline 27 & - & - & - & Diarrhea \\
\hline 28 & - & - & - & Diarrhea \\
\hline
\end{tabular}


Table 3: Hematological parameters of the different study groups

\begin{tabular}{|l|c|c|c|c|}
\hline Parameters & Group control & Group 2 & Group 3 & Group 4 \\
\hline Red cells (106 / mm3) & $6,49 \pm 0,05$ & $6,60 \pm 0,12$ & $6,55 \pm 0,07$ & $6,59 \pm 0,10$ \\
\hline Hemoglobin(g/dl) & $11,30 \pm 0,31$ & $11,80 \pm 0,18$ & $11,01 \pm 0,03$ & $11,42 \pm 0,19$ \\
\hline Hematocrit (\%) & $33,6 \pm 0,90$ & $34,01 \pm 0,10$ & $33,92 \pm 0,09$ & $33,12 \pm 0,80$ \\
\hline Mean corpuscular volume & $52,40 \pm 1,20$ & $53,03 \pm 0,9$ & $52,80 \pm 0,15$ & $52,75 \pm 0,78$ \\
\hline mean blood count hemoglobin & $17,17 \pm 1,10$ & $17,43 \pm 1,13$ & $18,03 \pm 1,20$ & $17,53 \pm 0,98$ \\
\hline Lymphocytes (\%) & 72,53 & 72,40 & 73,09 & 72,97 \\
\hline Platelets (thousand/ mm3) & $321,01 \pm 15,73$ & $320,87 \pm 5,61$ & $322,15 \pm 3,3$ & $320,17 \pm 7,09$ \\
\hline
\end{tabular}

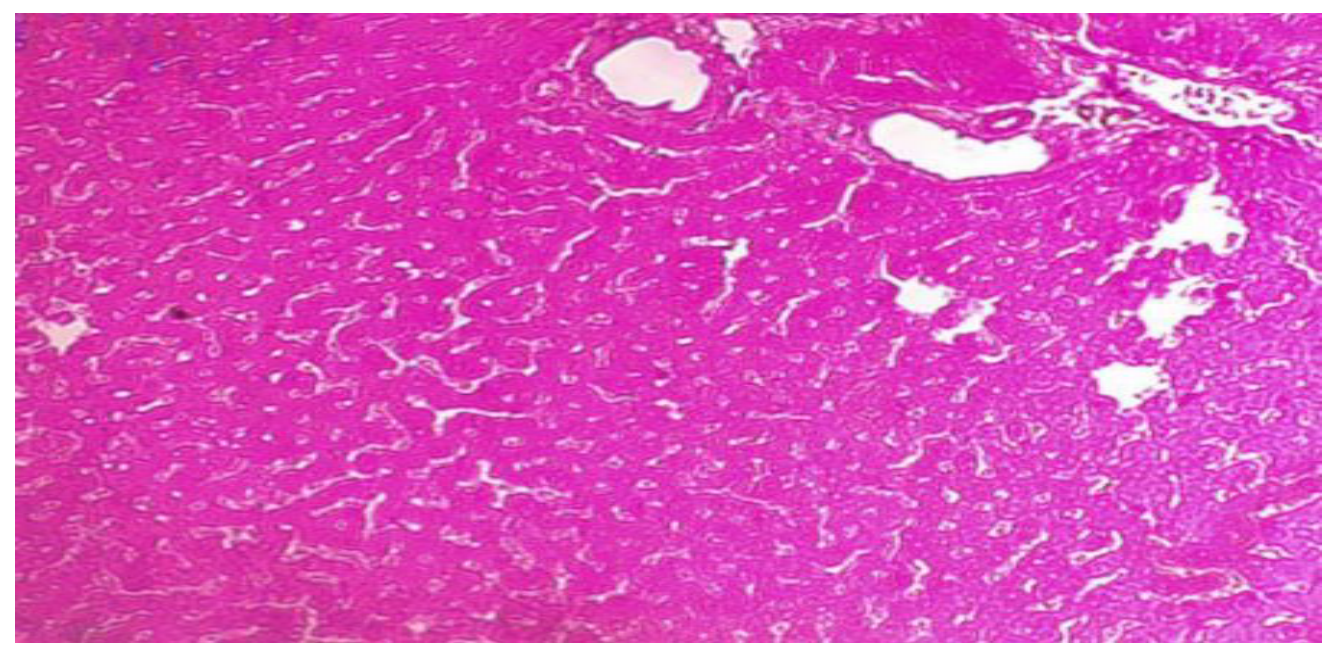

Figure 1: Histological section of a normal liver from rats of group control which received distilled water and fed regular diet

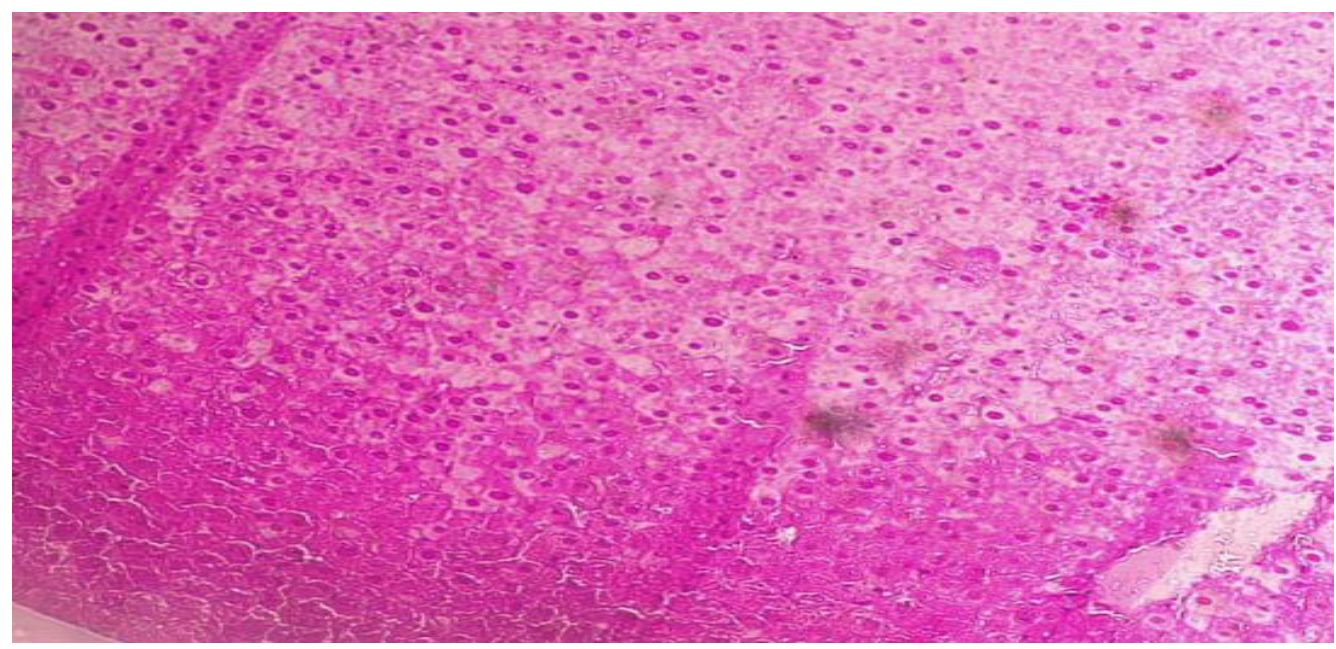

Figure 2: Histological section of a liver from rats which were received a dose of $3000 \mathrm{mg} / \mathrm{kg}$ of MEOL for 28 days showing steatosis. 


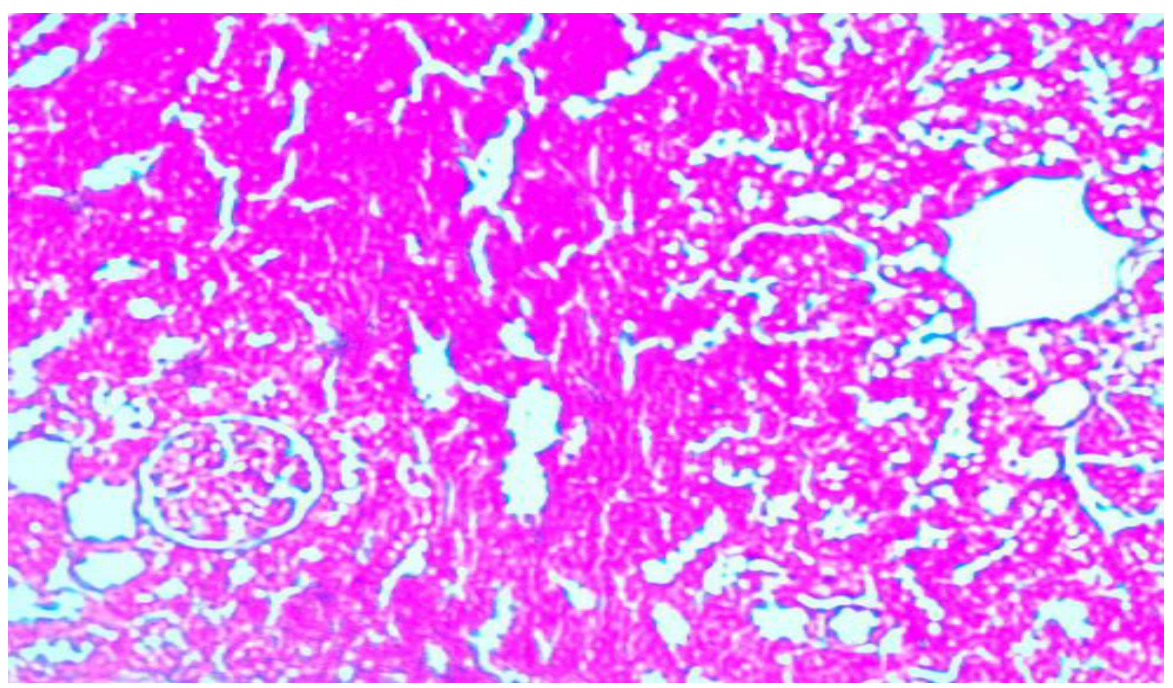

Figure 3: Histological section of a normal kidney from rats of group control which received distilled water and fed regular diet.

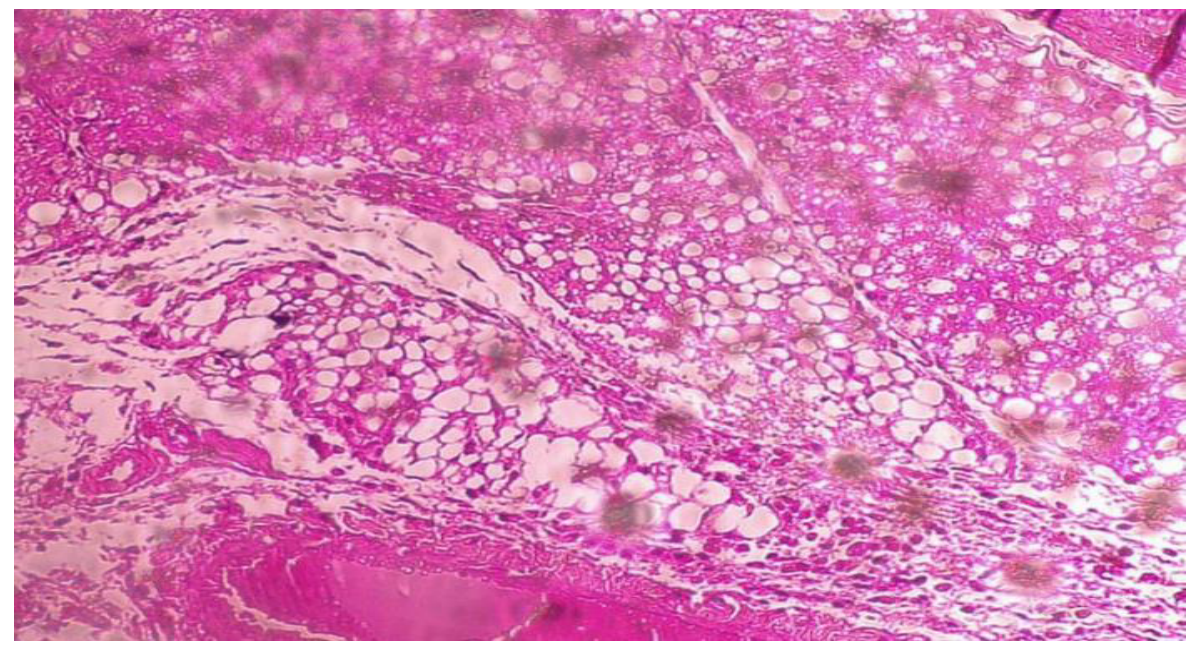

Figure 4: Histological section of a kidney from rats which were treated with a dose of $3000 \mathrm{mg} / \mathrm{kg}$ of MEOL for 28 days showing congestion and inflammation of the fat.

\section{Discussion}

Olive tree and its products such as olive oil is important component of Mediterranean diet. Its leaves have been used in order to prevent and treat some diseases in traditional medicine for ages[15]. The main active component in olive leaves is Oleuropein, a natural product of the secroiridoid group [16]. Oleuropein possesses a wide range of pharmacologic and health and health-promoting properties including antioxidant, immune- stimulant, cardioprotective, hypotensive, anti-inflammatory, antiarrhythmic, antioxidant, and anti-thrombic effects [17].

A single administration of increasing doses of $50,300,2000,5000 \mathrm{~kg} / \mathrm{mg}$ did not cause any death or signs of toxicity in Wistar rats. This result suggested that EMOL should be non-toxic and its DL50 being greater than $5000 \mathrm{mg} / \mathrm{kg}$ and can be classified in category 5 according to $\mathrm{OECD}[14]$. This study confirms the results found by another study which showed that the administration of a single dose of $2000 \mathrm{mg} / \mathrm{kg}$ of ethanolic extract of olive leaves did not induce mortality or any signs of toxicity among Wistar rats[18].

Repeated administration of EMOL over 28 days at different doses $(1000,2000$ and $3000 \mathrm{mg} / \mathrm{kg})$ did not cause significant changes in body weight in treated rats compared to control rats. Since, the changes in body weight can be used as an indicator of toxicity of chemicals and drugs [19]. Another study conducted by [18] showed that the treatment of rats by repeated doses of 100,200 and $400 \mathrm{mg} / \mathrm{kg}$ of ethanolic extract of olive leaves did not influence the body weight of the rats. 
After 13 days of treatment of the rats with a dose of $3000 \mathrm{mg} / \mathrm{kg}$ caused the appearance of some signs including diarrhea, manifestations of tremor and agitation. Similar studies with different durations and doses did not report any signs due to treatment of animals with olive leaves extracts [18], [20].

The hematological parameters are important in assessing toxicity of drugs in humans and animals [21]. In this study, hematological parameters measured did not show any differences between groups treated with doses of 1000,2000 and 3000 $\mathrm{mg} / \mathrm{kg}$ of olive leaves and control group.

Toxic nephropathies are defined as kidney injury caused by a few of medications, chemicals, alternative products, herbals and other toxin exposures [22]. The liver executes a few of important mechanisms involved in digestion, assimilation, storage, detoxification and elimination of toxin chemical in the body[23], [24]. the histopathological study of the organs of the rats treated with a dose of $3000 \mathrm{mg} / \mathrm{kg}$ of the extract of the olive leaves showed some modifications at the tissue level, specifically the congestion and inflammation of the fat in the kidneys and steatosis in the liver. Another study showed that sections of kidneys from rats treated with olive leaves extracts showed streaky hemorrhages and congestion in the cortical region. In the other hand, sections of liver showed fatty changes as well as hepatocellular necrosis[20].

\section{Conclusion}

The olive tree is a very popular plant especially in the Mediterranean regions, its leaves are widely used in traditional medicine. This study showed that the Single oral administration of the high dose extract did not cause any death in rats. whereas repeated administration of a dose of $3000 \mathrm{mg} / \mathrm{kg}$ for 28 days may affect the behavior of rats and may result in tissue scale changes in the kidneys and liver. These results call for more care and attention in the use of olive leaves in the medium and long term and in high doses. Therefore, further studies are needed to better assess the toxicity of olive leaves through subacute and chronic toxicity tests.

\section{Aknowledgement}

The authors extend their appreciation to Dr. Hajar Hechlaf; Specialist in Histology in El Idrissi Public Hospital, Kenitra. Morocco for reading histological sections of the study.

\section{References}

[1] S. Chen et al., "A renaissance in herbal medicine identification: From morphology to DNA," Biotech Adv, vol. 32, no. 7, pp. 12371244, Nov. 2014, doi: 10.1016/j.biotechadv.2014.07.004.

[2] A. Altemimi, N. Lakhssassi, A. Baharlouei, D. Watson, and D. Lightfoot, "Phytochemicals: Extraction, Isolation, and Identification of Bioactive Compounds from Plant Extracts," Plants, vol. 6, no. 4, p. 42, Sep. 2017, doi: 10.3390/plants6040042.

[3] T. Alelign, "Evaluation of Acute and Subacute Toxicity of Selected Traditional Antiurolithiatic Medicinal Plant Extracts in Wistar Albino Rats," p. 29.

[4] H. B. Sharif, M. D. Mukhtar, Y. Mustapha, G. Baba, and A. O. Lawal, "Acute and Subchronic Toxicity Profile of Euphorbia pulcherrima Methanol Extract on Wistar Albino Rats," Adv in Pharmac, vol. 2015, pp. 1-9, Feb. 2015, doi: $10.1155 / 2015 / 539646$.

[5] J.-W. Bae, D.-H. Kim, W.-W. Lee, H.-Y. Kim, and C.-G. Son, "Characterizing the human equivalent dose of herbal medicines in animal toxicity studies," J of Ethnophar, vol. 162, pp. 16, Mar. 2015, doi: 10.1016/j.jep.2014.12.023.

[6] L. Di Donna et al., "Secondary metabolites of Olea europaea leaves as markers for the discrimination of cultivars and cultivation zones by multivariate analysis," Food Chemistry, vol. 121, no. 2, pp. 492-496, Jul. 2010, doi: 10.1016/j.foodchem.2009.12.070.

[7] M. Cheurfa, H. H. Abdallah, R. Allem, A. Noui, C. M. N. Picot-Allain, and F. Mahomoodally, "Hypocholesterolaemic and antioxidant properties of Olea europaea $L$. leaves from Chlef province, Algeria using in vitro, in vivo and in silico approaches," Food and Chem Toxic, vol. 123, pp. 98-105, Jan. 2019, doi: 10.1016/j.fct.2018.10.002

[8] C. G. Guex, F. Z. Reginato, P. R. de Jesus, J. C. Brondani, G. H. H. Lopes, and L. de F. Bauermann, "Antidiabetic effects of Olea europaea $L$. leaves in diabetic rats induced by high-fat diet and low-dose streptozotocin," J of 
Ethnopharm, vol. 235, pp. 1-7, May 2019, doi: 10.1016/j.jep.2019.02.001.

[9] Y. Liu, L. C. McKeever, and N. S. A. Malik, "Assessment of the Antimicrobial Activity of Olive Leaf Extract Against Foodborne Bacterial Pathogens," Front. Microbiol., vol. 8, Feb. 2017, doi: 10.3389/fmicb.2017.00113.

[10] S. Bulotta et al., "Antioxidant and antigrowth action of peracetylated oleuropein in thyroid cancer cells," J of Mole Endocr, vol. 51, no. 1, pp. 181-189, Aug. 2013, doi: 10.1530/JME-12-0241.

[11] T. Vezza et al., "Immunomodulatory properties of Olea europaea leaf extract in intestinal inflammation," Mol Nutr \& Food Res, vol. 61 , no. 10 , p. 1601066, 2017, doi: https://doi.org/10.1002/mnfr.201601066.

[12] M. Barkaoui, A. Katiri, H. Boubaker, and F. Msanda, "Ethnobotanical survey of medicinal plants used in the traditional treatment of diabetes in Chtouka Ait Baha and Tiznit (Western Anti-Atlas), Morocco," Jourl of Ethnophar, vol. 198, pp. 338-350, Feb. 2017, doi: 10.1016/j.jep.2017.01.023.

[13] H. N. Mrabti et al., "Integrative herbal treatments of diabetes in Beni Mellal region of Morocco," J of Integr Med, vol. 17, no. 2, pp. 9399, Mar. 2019, doi: 10.1016/j.joim.2019.01.001.

[14] R. Jia et al., "Acute and subchronic toxicity as well as evaluation of safety pharmacology of modified pulsatilla granules," $J$ of Int Agr, vol. 16, no. 3, pp. 671-678, Mar. 2017, doi: 10.1016/S2095-3119(16)61401-6.

[15] N. Acar-Tek and D. Ağagündüz, "Olive Leaf (Olea europaea L. folium): Potential Effects on Glycemia and Lipidemia," Ann Nutr Metab, vol. 76 , no. 1 , pp. $10-15,2020$, doi: 10.1159/000505508.

[16] I. Hassen, H. Casabianca, and K. Hosni, "Biological activities of the natural antioxidant oleuropein: Exceeding the expectation - A minireview," J of Fun Foods, vol. 18, pp. 926-940, Oct. 2015, doi: 10.1016/j.jff.2014.09.001.

[17] S. N. El and S. Karakaya, "Olive tree ( Olea europaea ) leaves: potential beneficial effects on human health," Nutrition Reviews, vol. 67, no. 11, pp. 632-638, Nov. 2009, doi: 10.1111/j.1753-4887.2009.00248.x.

[18] C. G. Guex et al., "Safety assessment of ethanolic extract of Olea europaea L. leaves after acute and subacute administration to Wistar rats," Reg Toxic and Phar, vol. 95, pp. 395-399, Jun. 2018, doi: 10.1016/j.yrtph.2018.04.013.

[19] J. E. Hilaly, Z. H. Israili, and B. Lyoussi, "Acute and chronic toxicological studies of Ajuga iva in experimental animals," $J$ of Ethn, vol. 91, no. 1, pp. 43-50, Mar. 2004, doi: 10.1016/j.jep.2003.11.009.

[20] A.omar Sawsan et al., "Toxicity of olive leaves (olea europea) in Wstar Albino rats," As $J$ of An and Veter Adv, 2012.

[21] H. Rhiouani, J. El-Hilaly, Z. H. Israili, and B. Lyoussi, "Acute and sub-chronic toxicity of an aqueous extract of the leaves of Herniaria glabra in rodents," $J$ of Eth, vol. 118, no. 3, pp. 378-386, Aug. 2008, doi: 10.1016/j.jep.2008.05.009.

[22] M. A. Perazella, "Toxic Nephropathies: Core Curriculum 2010," Am J of Kid Dis, vol. 55, no. 2, pp. 399-409, Feb. 2010, doi: 10.1053/j.ajkd.2009.10.046.

[23] T. Y. Faremi, S. M. Suru, M. A. Fafunso, and U. E. Obioha, "Hepatoprotective potentials of Phyllanthus amarus against ethanol-induced oxidative stress in rats," Food and Chem Tox, vol. 46, no. 8, pp. 2658-2664, Aug. 2008, doi: 10.1016/j.fct.2008.04.022.

[24] M. Shahjahan, K. E. Sabitha, M. Jainu, and C. S. S. Devi, "Effect of Solanum trilobatum against carbon tetrachloride induced hepatic damage in albino rats," p. 6. 